\title{
A Review on Longterm Insomnia and its Association with Depression
}

\author{
Sohaib Siddiqui ${ }^{1}$, Sukaina Rizvi ${ }^{2}$, Talha Naser Jilani ${ }^{3}$ and Ali Mahmood Khan ${ }^{4 *}$ \\ ${ }^{1}$ Ross University School of Medicine, USA \\ ${ }^{2}$ Kings County Hospital Center, USA \\ ${ }^{3}$ Ziauddin University, Pakistan \\ ${ }^{4}$ Kings County Hospital Center, USA \\ Submission: June 11, 2018; Published: June 22, 2018 \\ *Corresponding author: Ali Mahmood Khan, Kings County Hospital Center, USA; Email: ali_mahmood_khan@hotmail.com
}

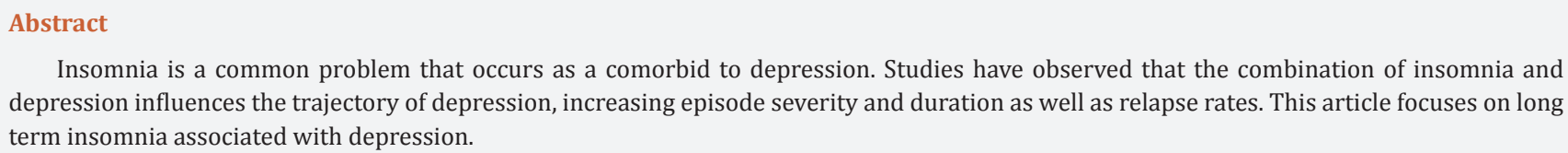

Insomnia is a common problem that occurs as a comorbid to depression. Studies have observed that the combination of insomnia and depression influences the trajectory of depression, increasing episode severity and duration as well as relapse rates. This article focuses on long term insomnia associated with depression.

\section{Introduction}

The relationship between insomnia and depression is complicated, and our knowledge has changed significantly in the past decade regarding the relationship between these two entities. Evidence from previous researches show that adolescents with disturbed sleep report more depression, anxiety, anger, inattention and conduct problems, drug and alcohol use, impaired academic performance, and suicidal thoughts and behaviors. Earlier, an epidemiological study has shown that persons with insomnia are at a higher risk of developing depression and anxiety disorders [1]. It was further shown that depression has not only qualitative but also quantitative effect on the sleep; severely depressed people have the worse sleep pattern as compared with those with mild-to-moderate depression [2]. Insomnia with depression can be considered as an intermediate subtype between pure depression and isolated insomnia [3]. Sleep disturbances are a common presentation in psychiatric disorders and specially disorders which affect the mood of a person.

\section{Discussion}

Insomnia is a common problem and affects nearly $10 \%$ of individuals [4]. Insomnia is a sleep disorder that is characterized by difficulty falling and/or staying asleep. It is the perception or complaint of inadequate or poor-quality sleep due to a number of factors, such as difficulty falling asleep, waking up frequently during the night with difficulty returning to sleep, waking up too early in the morning, or unrefreshing sleep. Various studies have noted insomnia to be quite a common condition with symptoms present in about $33-50 \%$ of the adult population [5]. Insomnia can be described by multiple ways for e.g primary and secondary, acute and chronic, onset insomnia and maintenance insomnia. Primary insomnia means that a person is having sleep problems that are not directly associated with any other health condition or problem. Secondary insomnia is also called comorbid insomnia. Secondary insomnia means that a person is having sleep problems because of something else, such as a health condition (like asthma, depression, arthritis, cancer, or heartburn); pain; medication they are taking; or a substance they are using (like alcohol).

Insomnia also varies in how long it lasts and how often it occurs. It can be short-term (acute insomnia) or can last a long time (chronic insomnia). Acute insomnia can last from one night to a few weeks. Insomnia is called chronic when a person has insomnia at least three nights a week for a month or longer. Some causes of acute insomnia are stress, illness, environmental factors, jet lag and some medications. The causes of chronic insomnia are depression, anxiety, chronic stress and pain or discomfort at night. Sleep onset insomnia is defined as difficulty initiating sleep; it is a common disorder with associated impairment or significant distress and is associated with daytime consequences. Sleep maintenance insomnia is a common, irritating sleep pattern in which person wakes up in the middle of the night and can't get back to sleep. 
Depression (major depressive disorder) is a common and serious medical illness that negatively affects how you feel the way you think and how you act. Depression causes feelings of sadness and/or a loss of interest in activities once enjoyed. It can lead to a variety of emotional and physical problems and can decrease a person's ability to function at work and at home. Depression symptoms can vary from mild to severe and can include: Feeling sad or having a depressed mood, loss of interest or pleasure in activities once enjoyed, changes in appetite, trouble sleeping or sleeping too much, loss of energy or increased fatigue, increase in purposeless physical activity (e.g., hand-wringing or pacing) or slowed movements and speech (actions observable by others), feeling worthless or guilty, difficulty thinking, concentrating or making decisions and thoughts of death or suicide. The lifetime prevalence of depression is as high as $20 \%$ in the general population worldwide with a female to male ratio of about 5:2. We have to assume that only about one third of patients are in treatment, maybe not due to ignorance, but due to the fact that symptoms may not be qualitatively different from those of everyday experience. Typically, the course of the disease is recurrent and most patients recover from major depressive episodes [6]. In patients who do recover, there is a high rate of recurrence and it has been found that approximately $75 \%$ of patients experience more than one episode of major depression within 10 years $[7,8]$. Suicide is a considerable risk for mortality in depression, and the rate of suicide is rather high between the age of 15 and 24 years [9]. The influence of chronic stress and adverse life events on the development of depression has been subject of numerous investigations and the work has been influenced by studies of the somatic and endocrine consequences of stress in animals [10]. The fact that major depression is more likely in females than in males can, however, not is explained by differing rates or sensitivities to stressful life events. Although women reported more interpersonal and men more legal- or work-related stressful life events, this cannot be attributed to the greater prevalence of major depression in females [11]. There is strong epidemiological evidence for a genetic contribution, especially for bipolar disorders, and heritability is estimated to be as high as $80 \%$ [12]. Studies in the field of neuroscience and biochemical substances have shown that they also play a part in the development of depression. Disrupted function in one or more steps of the chemical transmission taking place between neurons through synapses may be a crucial mechanism underlying depression. On the other hand, it is now well established that these mechanisms are targets of antidepressant action. The first major hypothesis of depression was formulated about 30 years ago and proposed that the main symptoms of depression are due to a functional deficiency of the brain monoaminergic transmitters norepinephrine (NE), 5-HT, and/or dopamine (DA), whereas mania is caused by functional excess of monoamines at critical synapses in the brain $[13,14]$. A variety of hormonal abnormalities, such as altered levels of Cortisol, growth hormone $(\mathrm{GH})$, or thyroid hormones, indicates the existence of endocrine disturbances, especially dysfunctions in the hypothalamic pituitary-adrenal (HPA) axis and/or the regulation of thyroid function.

Some people might think they are depressed when they are sad. But being sad is not the same as depression. The grieving process is natural and unique to each individual and shares some of the same features of depression. Both grief and depression may involve intense sadness and withdrawal from usual activities. They are also different in important ways such as in grief; painful feelings come in waves, often intermixed with positive memories of the deceased. In major depression, mood and/or interest (pleasure) are decreased for most of two weeks, in grief, selfesteem is usually maintained. In major depression, feelings of worthlessness and self-loathing are common. For some people, the death of a loved one can bring on major depression. Losing a job or being a victim of a physical assault or a major disaster can lead to depression for some people. When grief and depression co-exist, the grief is more severe and lasts longer than grief without depression. Despite some overlap between grief and depression, they are different. Distinguishing between them can help people get the help, support or treatment they need.

Now as we have discussed the two conditions separately we can look closely at the association of long term insomnia with depression. As many as $90 \%$ of patients with depression will have sleep quality complaints [15]. About two thirds of patients undergoing a major depressive episode will experience insomnia, with about $40 \%$ of patients complaining of problems initiating sleep (sleep onset difficulties), maintaining sleep (frequent awakenings), and/or early-morning awakenings (delayed or terminal insomnia), and many patients reporting all three [16]. Since insomnia is present in major depressive disorders it is sometimes termed as a secondary symptom of depression. Depression is identified as the most frequent cause of chronic insomnia in both clinical and epidemiological samples $[17,18]$. Since there is evidence about insomnia be a prodromal symptom in major depressive disorders, it suggests that sleep may be involved in the pathogenesis of depression. A number of longitudinal studies support the notion that insomnia is a risk factor for developing both first-onset and recurrent major depressive disorders. Insomnia impacts the trajectory of depression, increasing the duration and severity of depression. For e.g. poor sleep quality was associated with a poorer response to combined pharmacological and psychological treatments of depression [19]. Chronic sleep loss can lead to a loss of pleasure in life, one of the hallmarks of depression so when people can't sleep, they often become anxious about not sleeping and anxiety increases the potential for becoming depressed. Insomnia often shows up before a bout of depression strikes, serving as a useful warning sign. A worsening of insomnia can also signal depression.

Whether sleep disturbance is an integral part of a depressive episode is questionable. A large epidemiological study had also shown that all subjects with depression do not develop insomnia [20]. Functional imaging of the brain during a depressive 
episode provides the biological basis of sleep disturbance during depression and suggests that discrete brain areas are responsible for different symptoms in a depressed patient [21]. This is one reason why insomnia is not considered merely as a symptom of depression but considered comorbid. A number of studies also support the fact that insomnia is an independent illness that co-occurs with depression. First, insomnia is known to worsen dramatically when depression reaches a critical limit, further supporting the notion that they are in fact two disorders [22]. Second, insomnia had either preceded a depressive episode or led to a depressive episode or seen a residual symptom after treatment of depression [23]. The argument that is presented here is that if insomnia was not presented as a separated condition it would start with depression and remit with antidepressant therapy. Third, when depressed patients are subjected to psychological therapies for insomnia in addition to pharmacotherapy for depression, response is often better as compared with antidepressant therapy alone [24].

Studies had shown that depression severity was related to the number of nocturnal awakenings and the frequency of insomnia was associated with both depression and anxiety. Another study suggested that severe insomnia in depressed patients was associated with long duration of current depressive episode and higher HAM-D scores [25]. The duration of insomnia is a substitute marker of severity and we have found its positive correlation with total duration of depressive illness, number of depressive episodes, and length of the current depressive episode.

The treatment for clinical depression depends on how serious the mood disorder is. For instance, psychotherapy (talk therapy or counseling) combined with medications (antidepressants) is highly effective in treating depression. The antidepressants work to decrease symptoms of sadness or hopelessness while the psychotherapy helps improve coping skills and change negative attitudes and beliefs caused by depression. Talk therapy also works on coping skills to help you fall asleep more easily. Antidepressants such as SSRI'S, tricyclic antidepressants, SNRI and sedating antidepressants may be prescribed by the doctor. In most patients treated successfully with antidepressants, sleep symptoms improve in parallel with other depressive symptoms. However there is a minority of patients who experience an increase in symptoms of sleep disorders. Direct, comparisons confirm that more "sedating" antidepressant drugs such as nefazodone and amitriptyline improve sleep symptoms and polysomnography findings to a greater degree than SSRIs. A number of studies have suggested that sleep-focused psychotherapies and behavioral therapies are efficacious in patients with comorbid insomnia and depression. Recent, results from a small controlled clinical trial of depression pharmacotherapy combined with cognitive-behavioral therapy for insomnia showed improved sleep and depression outcomes compared with pharmacotherapy combined with an inactive therapy control.

\section{Conclusion}

Cross-sectional studies show a strong relationship between symptoms of depression and insomnia, and insomnia is longitudinally associated with the development of depression and poor treatment outcomes. Recent studies have demonstrated that both pharmacological and non-pharmacological interventions for insomnia may favorably reduce and possibly prevent depression. Together, these findings suggest that sleeprelated symptoms that are present before, during, and or after a depressive episode are potentially modifiable factors that may play an important role in achieving and maintaining depression remission. In the conclusion we can say that insomnia is a frequent comorbid in depressive disorders. They usually follow depressive symptoms. We can also conclude that if long term insomnia is left untreated it can lengthen the depressive illness as well as increase the frequency of it.

\section{References}

1. Taylor DJ, Lichstein KL, Durrence HH, Riedel BW, Bush AJ (2005) Epidemiology of insomnia, depression, and anxiety. Sleep 28(11): 1457-1464.

2. Gupta R, Dahiya S, Bhatia MS (2009) Effect of depression on sleep: Q0 qualitative or quantitative? Indian J Psychiatry 51(2): 117-121.

3. Buysse DJ, Angst J, Gamma A, Ajdacic V, Eich D, et al. (2008) Prevalence, course and comorbidity of insomnia and depression in young adults. Sleep 31(4): 473-480.

4. Pigeon WR (2010) Diagnosis, prevalence, pathways, consequences and treatment of insomnia. Indian J Med Res 131: 321-332.

5. Ancoli IS, Roth T (1999) Characteristics of insomnia in the United States: Results of the 1991 National Sleep Foundation Survey I. Sleep 2: S347-S353.

6. Weissman MM, Bland RC, Canino GJ (1996) Cross-national epidemiology of major depression and bipolar disorder. JAMA 276(4): 293-299.

7. Angst J (1992) How recurrent and predictable is depressive illness? In: Montgomery SA, Rouillon F, (Eds.), Long-Term Treatment in Depression, John Wiley Publication, New York, USA.

8. Lavori PW, Keller MB, Scheftner W, Fawcett J, Mueller Tl (1994) Recurrence after recovery in unipolar MDD. An observational followup study of clinical predictors and somatic treatment as a mediating factor. Int J Methods Psychiatry Res 4(4): 211-229.

9. Wong ML, Licinio J (2001) Research and treatment approaches to depression. Nat Rev Neurosci 2(5): 343-351.

10. Paykel ES (2001) The evolution of life events research in psychiatry. J Affect Disord 62(3): 141-149.

11. Kendler KS, Thornton LM, Prescott CA (2001) Gender differences in the rates of exposure to stressful life events and sensitivity to their depressogenic effects. Am J Psychiatry 158(4): 587-593.

12. Berrettini W (1999) Molecular linkage studies in bipolar disorder. Dialogues Clin Neurosci 1(1): 12-21.

13. Schildkraut JJ (1965) The catecholamine hypothesis of affective disorders: a review of supporting evidence. Am J Psychiatry 122(5): 509-522.

14. Matussek N (1972) Biochemistry of depression. J Neural Transm 33: 223-234. 
15. Tsuno N, Besset A, Ritchie K (2005) Sleep and depression. J Clin Psychiatry 66: 1254-1269.

16. Perlis ML, Giles DE, Buysse DJ, Thase ME, Tu X, et al. (1997) Which depressive symptoms are related to which sleep electroencephalographic variables? Biol Psychiatry 42(10): 904-913.

17. Buysse DJ, Reynolds CF, Kupfer DJ (1994) Clinical diagnoses in 216 insomnia patients using the International Classification of Sleep Disorders (ICSD), DSM-IV and ICD-10 categories: a report from the APA/NIMH DSMIV Field Trial. Sleep 17(7): 630-637.

18. Ohayon MM, Caulet M, Lemoine P (1998) Comorbidity of mental and insomnia disorders in the general population. Cornpr Psychiatry 39(4): 185-197.

19. Dew MA, Reynolds CF, Houck PR (1997) Temporal profiles of the course of depression during treatment. Predictors of pathways toward recovery in the elderly. Arch Gen Psychiatry 54(11): 1016-1024.

20. Milak MS, Parsey RV, Keilp J, Oquendo MA, Malone KM, et al. (2005) Neuro-anatomic correlates of psychopathologic components of major depressive disorder. Arch Gen Psychiatry 62(4): 397-408.
21. Watanabe N, Furukawa TA, Shimodera S, Morokuma I, Katsuki F, et al. (2011) Brief behavioral therapy for refractory insomnia in residual depression: An assessor-blind, randomized controlled trial. J Clin Psychiatry 72(12): 1651-1658.

22. O Brien EM, Chelminski I, Young D, Dalrymple K, Hrabosky J, et al. (2011) Severe insomnia is associated with more severe presentation and greater functional deficits in depression. J Psychiatr Res 45(8): 1101-1105.

23. Rush AJ, Armitage R, Gillin JC (1998) Comparative effects of nefazodone and fluoxetine on sleep in outpatients with major depressive disorder. Biol Psychiatry 44(1): 3-14.

24. Lichstein KL, IMau SD, Mc Crae CS, Stone KC (2005) Psychological and behavioral treatments for secondary insomnias. In: Kryger $\mathrm{MH}$, Roth T, Dement WC (Eds) Principles and Practices of Sleep Medicine, Philadelphia, USA.

25. Manber R, Edinger JD, Gress JL, San Pedro Salcedo MG, Kuo TF, et al. (2008) Cognitive behavioral therapy for insomnia enhances depression outcome in patients with comorbid major depressive disorder and insomnia. Sleep 31(4): 489-495.

\section{Your next submission with Juniper Publishers will reach you the below assets}

- Quality Editorial service

- Swift Peer Review

- Reprints availability

- E-prints Service

- Manuscript Podcast for convenient understanding

- Global attainment for your research

- Manuscript accessibility in different formats ( Pdf, E-pub, Full Text, Audio)

- Unceasing customer service

Track the below URL for one-step submission https://juniperpublishers.com/online-submission.php 